\title{
Health Education in Saudi Arabia Historical overview
}

Anwar Al-Hashem

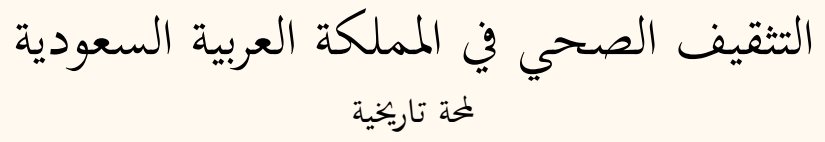

أنوار الهاشم

ABSTRACT: This article provides a historical overview of the evolution of health education in Saudi Arabia. It outlines milestones in the development of the health education profession and traces the roles of various health sectors and their achievements in the health education field. Additionally, this review seeks to describe the status of health education professionals in Saudi Arabia.

Keywords: History; Health Educators; Healthcare Sector; Health Promotion; Public Health; Government Agencies; Saudi Arabia.

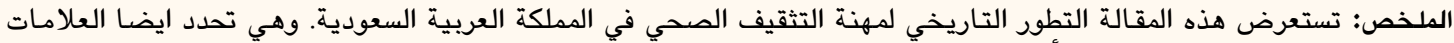

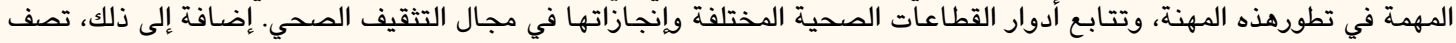

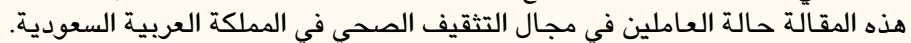
كلمات مفتحاحية: التاريخ؛ المُثَقِفِن الصحِيِين؛ قطاع الرعاية الصحية؛ تعزيز الصحة؛ الصحة العامة؛ الوكالات الحكومية؛ العربية السعودية.

$\mathrm{T}$ He World health organization (Who) defines health education as "any combination of learning experiences designed to help individuals and communities improve their health, by increasing their knowledge or influencing their attitudes". Health education provides opportunities for both individuals and communities to acquire the necessary information/skills required to make health decisions or change health behaviours. ${ }^{2}$ Between the 1970s and 1990s, many Gulf Corporation Council countries witnessed a remarkable growth in their healthcare sectors, including Saudi Arabia. ${ }^{3}$ Since then, the government of Saudi Arabia has made efforts to improve healthcare through health education and this remains a focal point of healthcare policies today. In this review, a historical overview of health education in Saudi Arabia is provided, including more recent milestones in this field, the role of various health sectors in health education and the current status of health education professionals in Saudi Arabia.

\section{Historical Background of Health Education Initiatives}

In the early 1900s in Saudi Arabia, most people sought help from local traditional healers to treat various common health issues, such as back and abdominal pain, flatulence, tooth pain, infertility, depression and headaches. Common traditional practices included reciting the Holy Quran, ingesting certain herbs or teas, cautery and cupping., ${ }^{4,5}$ Before 1925, the territory which now makes up modern-day Saudi Arabia was not yet completely under the control of the ruler King Abdulaziz Ibn Saud; as a result, some regions were characterised by a lack of political stability and security. During his reign, King Abdulaziz established the Directorate of Public Health in the first Saudi Arabian capital, Makkah, in the Hejaz region; this directorate was the cornerstone of the Saudi Arabian healthcare system and aimed to promote health and safety during the Hajj season. ${ }^{6}$ The annual Hajj, or pilgrimage season, attracts thousands of Muslims to western Saudi Arabia to practice their faith. Due to the large numbers of pilgrims gathering for Hajj, both communicable and non-communicable disease outbreaks still occur, including cholera, malaria, poliomyelitis, meningococcal disease, respiratory tract infections, blood-borne diseases, heat exhaustion and heat stroke. $^{7}$

In 1926, King Abdulaziz issued another decree founding the Health and Emergency Department (HED); this department included doctors and other professionals, such as a general inspector, a chief pharmacist and various administrative employees 
(e.g. statisticians, record keepers and clerks). ${ }^{6}$ The HED was responsible for promoting public and environmental health, establishing hospitals and healthcare centres, managing human resources within these centres, legislating policies and procedures to ensure public safety and promoting medicine and pharmacology standards. ${ }^{8}$ Between 1926 and 1949, approximately 25 clinics, 34 health centres and 11 hospitals were established throughout Saudi Arabia, as well as one microbiology institute in Ta'if. ${ }^{6}$ Although the HED played a role in providing and monitoring free healthcare access for Hajj pilgrims and the general Saudi Arabian population, insufficient funding and resources unfortunately limited its overall achievements. Epidemics of certain communicable diseases-such as smallpox, measles, meningitis, diphtheria, scarlet fever, cholera, plague and mumpsremained persistently high among both members of the general public and pilgrims. ${ }^{9}$

In the 1920s, the Directorate of Public Health identified the lack of health awareness among the Saudi Arabian public as a key issue. Specifically, awareness of life-threatening epidemic diseases and their modes of transmission were viewed solely as the focus of health professionals and few health education materials on subjects such as personal hygiene, cleanliness and the prevention of communicable diseases were available at that time. ${ }^{6}$ As a result, several newspaper articles and announcements on preventative measures, symptoms and causes of communicable diseases as well as general information on protection against malaria epidemics were published in 1925, 1926 and $1930 .{ }^{6}$ During the Hajj season in 1929, the Directorate of Public Health issued a leaflet on various epidemic diseases, including protection and control measures. It also published the first guidelines on health-related personal hygiene, sanitation and cleanliness during the Hajj season. ${ }^{6}$ In the 1940s, several announcements followed with general instructions on the safe preparation/handling of food and the cleanliness of food sale premises as well as health instructions for barbershops (e.g. cleanliness of equipment). Concurrently, the HED conducted two free vaccination campaigns against smallpox and typhoid targeted at members of the public and pilgrims alike. Additionally, residentassisted cleanliness campaigns were initiated in Muna every year before Hajj season. ${ }^{6}$ These health initiatives were significant, as they helped to educate the public without relying on written media-this was important given that the literacy rate in Saudi Arabia was very low up until the 1970s (approximately 15\% for men and 2\% for women). ${ }^{10}$

Twenty-five years after the creation of the HED, the Saudi Arabian Ministry of Health $(\mathrm{MOH})$ was established. ${ }^{8}$ During the 1950s, malaria control and prevention campaigns/programmes were introduced through the collaborative efforts of the $\mathrm{MOH}$, World Health Organization (WHO) and Arabian American Oil Company (Aramco). ${ }^{11}$ These nation-wide programmes established a curative and preventative model of healthcare that was then disseminated to the general population. There were over 28 such programmes, whose strategies involved spraying crops with dichlorodiphenyltrichloroethane to reduce the mosquito population as well as administering blood tests and providing antimalarial drugs for infected patients. ${ }^{6}$ In 1954, school health units were introduced as another health education and prevention effort. To begin with, these units focused only on male pupils, teachers and employees of the Ministry of Education; at that time, females were not allowed to attend schools. Furthermore, school health units were available only in urban areas such as Riyadh, Makkah and Jeddah, and mainly provided curative services and a few preventative services related to immunisation, counselling and health lectures. ${ }^{6}$

Due to the scarcity of resources, the widespread distribution of the population and the vast geographical area of Saudi Arabia, the healthcare system in the 1960s faced heavy challenges, for example, the high mortality rate among under-five-year-olds (250 deaths per 1,000 live births in 1960). ${ }^{12}$ However, due to the massive amount of oil revenue generated in the 1970s, the government was subsequently able to dramatically improve the industrial, agricultural, transportation, communication, healthcare and education sectors. ${ }^{3}$ Beginning in 1970, the first five-year development plan greatly improved the national healthcare system and implemented compulsory vaccination plans for infants and children; this in turn helped reduce the under-five mortality rate (19.1 deaths per 1,000 live births in 2011). ${ }^{12}$

The 1980s were a very successful decade for the Saudi Arabian healthcare system, during which the third development plan saw the construction of numerous hospitals and primary healthcare centres. From 1985-1987, a total of 377 healthcare facilities were built, of which 65 were hospitals and the rest were primary healthcare centres. ${ }^{13}$ However, in the late 1980s and mid-1990s, during the course of the fourth and fifth development plans, both governmental and private healthcare growth slowed. ${ }^{13}$ The two main reasons for this decline were the expenses associated with the curative model and the relatively flat $\mathrm{MOH}$ budget, which did not allow for price fluctuations. Notably, these factors contributed to the suspension of one of the largest medical facilities in Saudi Arabia, the King Fahad Medical City. ${ }^{13}$ Although 
previously the healthcare sector had concentrated on communicable diseases, social and economic factors in the 1980s contributed to a gradual shift in focus to chronic diseases and quality of life-related conditions. ${ }^{6}$ Diabetes, acquired immune deficiency syndrome and heart disease were among the first conditions to be tackled; in 1984 alone, the $\mathrm{MOH}$ supervised 121 programmes intended to increase health awareness among the public through mass media, symposiums and meetings. ${ }^{6}$ Additionally, public health policy was also changed after a royal decree was issued prohibiting advertisements and publications supporting cigarettes and increasing the duty on tobacco and its derivatives. ${ }^{6}$

Health education activities gradually increased from 1985 to the late 1990s. ${ }^{6}$ By 1997, health education was perceived much more positively by health professionals and the public alike. This change in perception was due to the success of certain prevention and control programmes (e.g. tuberculosis programmes) and the increased publicity and mass media coverage of health education programmes and activities around the country. ${ }^{6}$ In 1998, the school health units expanded their services to cover female schools in rural and urban areas. These units provided preventative services by general physicians, dentists, nurses and health educators to promote a healthy lifestyle including information on nutrition and a balanced diet, dental health, personal health/hygiene, smoking cessation, physical activity, safety/injury prevention and mental health. ${ }^{6}$

By the late 1990s, more than 16 Saudi Arabian health and medical journals were in circulation, targeting both health professionals and the general public. ${ }^{6}$ These included the Health Education Journal (1997), a monthly journal published by a security forces hospital; the Nutrition Bulletin (1997), a monthly leaflet issued by the MOH; and the Saudi Heart Association Bulletin (1989), a quarterly publication printed by the King Saud University. Moreover, in 2014 alone, the $\mathrm{MOH}$ circulated more than four million health booklets, leaflets, posters and announcements and participated in 9,000 national and international health awareness activities to combat smoking, cancer and diabetes. ${ }^{14}$

\section{Modern Milestones in the Development of Health Education}

In 2001, the Health Education Symposium was organised by the King Khaled Eye Specialist Hospital in Riyadh. ${ }^{15}$ This was the first national gathering of health educators in Saudi Arabia and was a significant event in securing support and recognition of the importance of health education. Between 2001 and 2011, nine symposiums were held. ${ }^{15}$ Various speakers and workshop instructors at these symposiums were key in influencing health education promotion in the Arab world and most attendees were health educators from different sectors. Recommendations arising from these symposiums were recognised by the Ministry of Civil Services and the Saudi Commission for Health Specialties and helped mobilise efforts to acknowledge health education problems and devise solutions. Furthermore, these symposiums facilitated the development of major commissions and organisations, such as the National Commission of Health Education directed by the $\mathrm{MOH}$ and the Charitable Society of Health Communication. ${ }^{15}$

Heightened recognition of the importance of health educators has led to an increased number of health education courses and seminars aiming to further improve the understanding of health education objectives. In 2007, a preventative medicine department of the $\mathrm{MOH}$ created a programme to provide primary health centre practitioners with greater health education skills; they successfully trained over 100 workers from different primary health centres on health education principles. ${ }^{16}$ Furthermore, in 2007, the $\mathrm{MOH}$ announced that more than 4,500 health education positions in primary health centres needed to be filled. ${ }^{16}$

In terms of health education theories, most activities and programmes conducted by health education specialists in hospital settings in Saudi Arabia since the 1990s have been based on medical concepts. ${ }^{15}$ These usually involve the identification and ranking of the various causes of mortality and morbidity in a society and then targeting these causes via medical interventions. ${ }^{17}$ In other settings, most health education activities and interventions are based on behavioural change theories; the dominant model currently used by health education professionals is the health belief model, a psychological model which explains and predicts health-related behaviours at the individual level. ${ }^{15}$

\section{Healthcare Sectors and their Role in Health Education}

Healthcare in Saudi Arabia is divided into two main sectors, governmental and private. In 2012, the $\mathrm{MOH}$ operated $63 \%$ of all hospitals in the country, while $24 \%$ were operated by other governmental agencies, such as the Ministry of Defence and Aviation, Ministry of Education and the National Guard. In contrast, 13\% of hospitals fell under the private sector. ${ }^{13}$ 


\section{GOVERNMENTAL SECTOR}

\section{Ministry of Health}

The $\mathrm{MOH}$ is responsible for operating and monitoring health systems in Saudi Arabia and is the biggest healthcare provider in Saudi Arabia, receiving 7\% of the total governmental annual budget. ${ }^{14}$ It aims to improve the health of the population by developing health laws, regulatory legislation and policies to serve the health system, conducting health research and training professionals to work in the health system. ${ }^{8}$ The $\mathrm{MOH}$ plays a role in establishing, funding, coordinating and delivering health education and public health promotion programmes. In 1998, the $\mathrm{MOH}$ established the Healthy Cities Project which aimed to promote school and occupational health in 20 cities with a focus on physical activity and nutrition. ${ }^{18}$ The $\mathrm{MOH}$ also trains and educates health professionals on health education and health promotion strategies. Symposiums have been conducted to educate and share information on health education and its importance in healthcare. Recently, the $\mathrm{MOH}$ has assumed administrative responsibility over school health units, originally governed by the Ministry of Education. ${ }^{19}$

Health education efforts by the $\mathrm{MOH}$ face several challenges, most of which are related to the quantity and quality of health education activities. These include the unequal distribution of health education programmes, with most programmes in Saudi Arabia held in large cities such as Riyadh, Jeddah and Dammam, and only a few located in rural areas. Overall, the number of national health education programmes is insufficient to support the high demand in both rural and urban areas. ${ }^{20}$ Moreover, the quality of health education activities/programmes, in particular those managed by primary health centres, suffers from a lack of clearly communicated health goals, theory-based interventions, communication behavioural-related outcomes and comprehensiveness. ${ }^{9}$ Health education activities are usually not based on valid assessment methods but rather on individual perceptions of various health issues and demands. ${ }^{15}$ Even when assessments with valid methods are carried out, they are rarely suitable or rigorous enough to demonstrate programme effectiveness, which can affect the continuity of the programme. ${ }^{15}$ Other concerns include a shortage of human resources, lack of training opportunities for healthcare providers and unmet training demands in health education strategies and programme planning skills. Additionally, programmes are not routinely updated with regards to recent advances in the field of health promotion. ${ }^{21}$

\section{Other governmental sectors}

Other governmental healthcare agencies in Saudi Arabia include the National Guard hospitals, Aramco hospitals, Armed Forces hospitals, Security Forces Hospital and Royal Commission hospitals in Jubail and Yanbu. Research, specialised and university hospitals also exist, such as the King Khaled Eye Specialist Hospital, King Faisal Specialist Hospital \& Research Centre in Riyadh and Jeddah, King Abdulaziz University Hospitals in Riyadh and Jeddah, King Khalid University Hospital in Riyadh and King Fahad University Hospital in Al-Khobar.9 Altogether, over 39 hospitals and hundreds of primary health centres are operated by non- $\mathrm{MOH}$ governmental agencies, with approximately 10,822 beds. ${ }^{9}$ Most of the patient health education and promotion efforts in Saudi Arabia are organised by health education departments in these hospitals. In the early 1990s, the King Khaled Eye Specialist Hospital, Security Forces Hospital and Aramco hospitals were among the first to start health education activities (e.g. patient education and community health awareness activities). Afterwards, other hospitals and medical cities followed suit. ${ }^{6,15}$

Previously, most health education in Saudi Arabia focused on diabetes management, cardiovascular diseases, the early detection and treatment of cancer, diet and weight management, physical activity and the prevention or treatment of the diseases in which each hospital specialised. ${ }^{9}$ In the early 1990s, most hospitals did not have health education specialists; as a result, other healthcare professionals performed patient and community education tasks. ${ }^{15}$ Only a few hospitals in Saudi Arabia recruited health educators from different educational backgrounds, such as nursing, social work and other allied health departments, to conduct oneon-one education sessions, lectures and workshops, design printed materials and participate in national and international health events. By providing training and supervision and sharing their experiences, these health educators paved the way for new interns and graduates of health education programmes, many of whom now have official positions working in health education/patient education departments. ${ }^{15}$

\section{PRIVATE SECTOR}

The private sector received strong support from the Saudi government in the 1980s. Interest-free loans were offered to those interested in establishing healthcare facilities, such as hospitals, private clinics and pharmaceutical care centres. ${ }^{22}$ Currently, there are more than 141 private hospitals with 15,664 beds and 2,412 private polyclinics in Saudi Arabia; notably, 
$85.6 \%$ and $47.5 \%$ of these polyclinics and private hospitals, respectively, are located in the urban cities of Riyadh and Jeddah. ${ }^{14}$ The role of the private sector in health education in Saudi Arabia is varied and largely dependent on the quantity and quality of healthcare. Only a few private hospitals employ specialised health educators to carry out health education and patient education activities. The responsibility of patient education activities is often left to individual health providers, who spend time in their clinics to educate patients or caregivers on health issues. ${ }^{6}$

\section{HEALTH EDUCATION COMMISSIONS AND ORGANISATIONS}

The first governing body of health education in Saudi Arabia was the Departments of Health Education, established in 1997.23 This group was comprised of personnel from a number of health institutes, including the King Khaled Eye Specialist Hospital, Security Forces Hospital, King Faisal Specialist Hospital \& Research Centre, Prince Sultan Military Medical City, MOH Dental Specialist Centre, King Abdulaziz University Hospital, $\mathrm{MOH}$ General Directorate of Health Affairs, Sulaymaniyah Children's Hospital, King Saud Hospital for Chest Diseases, Al-Amal Complex for Mental Health and Al-Salama Hospital. ${ }^{15}$ The goal of the Departments of Health Education was to form a coordinated organisation that could provide health education activities and solve national health education issues. Before it was shut down in 2004, the Departments of Health Education was the basis of the subsequent establishment of the Charitable Society for Health Communication in 2006. ${ }^{15}$ The Charitable Society for Health Communication was the first health education association in Saudi Arabia to dedicate itself solely to providing resources on health education and health promotion. ${ }^{23}$ This organisation provides advisory services-including programme planning, health education research, policy development and general support-to members of the government and private health sectors, teachers and media personnel. ${ }^{23}$

In 2013, the National Committee of Health Education was founded in Riyadh. Operating on a similarly large scale as the Charitable Society for Health Communication, the National Committee of Health Education was established to provide countrywide health education strategies and policies in relation to health promotion. ${ }^{24}$ Their goal is to prepare national health assessments, prioritise health awareness goals, develop health awareness action plans and evaluation systems and provide laws and procedures to coordinate health activities. All of these efforts fall under the scope of the $\mathrm{MOH}$ and other health organisations and committees concerned with health education. ${ }^{24}$
Currently, there are 69 charitable and noncharitable health associations in Saudi Arabia, with 55 charitable health associations registered with the Ministry of Social Affairs and 14 non-charitable health associations affiliated with King Saud University. ${ }^{25}$ All of these associations strive to spread health awareness among professionals and the general public.

\section{Current Status of Health Educators}

Health educators in Saudi Arabia can work in the $\mathrm{MOH}$, other governmental sectors, the private sector, academic sector or in health associations. The most recent statistics released by the $\mathrm{MOH}$ in 2014 do not specify health educators as a stand-alone professional category. ${ }^{14}$ It is therefore difficult to estimate the number of health educators working in various sectors in Saudi Arabia.

In April 2001, the Ministry of Civil Services, which is responsible for creating and updating job classifications, included health education positions under health researcher or health technician positions; graduates with Bachelor's degrees in health education were hence considered qualified to fill these positions. ${ }^{26}$ In response, advocates of health education recommended that the Ministry of Civil Services create a special health education position that could only be filled by highly qualified health educators. In 2004, the Saudi Commission for Health Specialties included health education as a classification of health worker. ${ }^{15}$ This classification is an important contributor to the recognition of health education as a profession in the field of healthcare. In 2014, the latest update of the health professional classification guide and professional registry approved three levels of classification: specialist, senior specialist and consultant. At each level, certain qualification and work experience requirements must be met. ${ }^{26}$ Specifically, health educators are registered as health education specialists if they have a Bachelor's degree in health education; senior specialists if they have earned a Master's degree along with two years of experience in the field; and consultants if they have a Ph.D. and at least three years of work experience. ${ }^{26}$ Regardless of subspecialty, health educators and public health personnel must undergo at least 20 hours of continuous education per year to fulfil requirements.

Article 15/11 of the Saudi Commission for Health Specialties guidelines includes health education within the following subspecialties: behaviour health education, prevention health education, school health education, patient health education, occupational health education and safety, health education in the 
Table 1: List of Saudi Arabian universities currently offering public health, health education or community health degree programmes

$\begin{array}{lc}\begin{array}{l}\text { University name and year } \\ \text { established }\end{array} & \begin{array}{c}\text { Programme title and } \\ \text { year initiated }\end{array} \\ \text { Umm Al-Qura University (1949) } & \text { Health Promotion (2011) } \\ \text { King Saud University (1957) } & \begin{array}{c}\text { Health Education (1981) } \\ \text { Public Health* }\end{array} \\ \text { King Faisal University (1975) } & \text { Public Health (2011) } \\ \text { Qassim University (2002) } & \text { Public Health (2011) } \\ \text { King Saud bin Abdulaziz } & \text { Public Health (2010) } \\ \text { University (2005) } & \text { Public Health* } \\ \text { University of Hail (2005) } & \text { Community Health* } \\ \text { Al Baha University (2006) } & \text { Public Health* } \\ \text { King Khalid University (2007) } & \text { Health Education \& } \\ \text { Princess Nourah bint } & \text { Promotion (2008) } \\ \text { Abdulrahman University (2008) } & \text { Health Education* } \\ \text { Jazan University (2011) } & \text { Public Health* } \\ \text { Prince Sattam bin Abdulaziz } & \text { Public Health* } \\ \text { University (2011) } & \text { Saudi Electronic University (2011) } \\ \text { "Programme not yet started or not yet listed on the university website } \\ \text { as of 2014. }\end{array}$

mass media, global health education, nutrition health education and environmental health education. ${ }^{26}$ Moreover, the Saudi Commission for Health Specialties classifies public health practitioners with similar subspecialties into various domains, including behavioural, environmental, global and nutritional domains. Specifically, Article 15/12 includes public health as a general specialty with the following subspecialties: behavioural public health, biostatistics, environmental public health, epidemiology, global and international public health, maternal and child public health, nutrition public health, public health laboratory practice, public health policy, public health practice, dental public health and nursing public health. ${ }^{26}$

\section{PROFESSIONAL QUALIFICATIONS}

Currently, 12 universities in Saudi Arabia offer either postgraduate or baccalaureate degrees in health education or public health [Table 1]. As public education is free for all Saudi Arabian nationals, none of these universities charge tuition fees, apart from the Saudi Electronic University. Moreover, full-time students who sustain grade point averages of over 2.0 out of 4.0 are allocated a monthly stipend of USD $\$ 264 .{ }^{27}$ The King Saud bin Abdulaziz University for Health Sciences offers a Master's degree in public health. Their curriculum, which is accredited by the Saudi Commission for Health Specialties, is a two- year programme consisting of 43 credit hours which includes the completion of a research project. $^{28}$ Other universities in Saudi Arabia that have only been established within the last six years have either started offering or are in the process of developing baccalaureate degrees in public health. Most of these universities, excluding King Saud University and King Saud bin Abdulaziz University for Health Sciences, either offer or plan to offer this degree under the aegis of applied health sciences colleges or public health/health informatics departments. Overall, in the coming years, these universities will provide Bachelor's degrees in public health, health education, health promotion or community health.

The College of Applied Medical Sciences (CAMS) at King Saud University in Riyadh was the first to offer a baccalaureate degree in health education and was also the forerunner in offering this degree to female students in $1981 .{ }^{29}$ At CAMS, the degree is undertaken over the course of four and a half years (nine semesters) plus a year-long mandatory internship. Students learn basic sciences such as anatomy, physiology, microbiology, epidemiology, biostatistics, physics and biochemistry as well as health sciences such as nutrition, emergency care, childhood growth and development, maternity/childcare and healthcare delivery. ${ }^{29}$ They also take technology and media in healthcare courses. Other basic courses in public health include civilization disease prevention, infectious diseases, demography, occupational health and safety, Islamic political system fundamentals, family planning, environmental health, substance abuse and personal health. ${ }^{29}$ Various health education courses are offered every semester, including community health, health education theories, social concepts of health education, the psychological basis of health education, consumer health education, health education methodologies, systems approach to health education, dental health education, school health education, health education management, health education in health services and health education research. ${ }^{29}$ Between 2003-2010, 114 students graduated from CAMS with baccalaureate degrees in health education, with an average of 16 students per year. ${ }^{29}$

As with nursing and other health/medical professions, qualifications obtained from outside Saudi Arabia are reviewed and evaluated by the Certificates Equivalency Committee of the Ministry of Education to ensure that the obtained degree is the equivalent of its counterpart in the Saudi Arabian higher education system. ${ }^{29}$ This generally takes place before the individual is employed as a health education professional. ${ }^{30}$ 


\section{Conclusion}

Considerable effort on the part of governmental and private health organisations has led to numerous milestones in the management, administration and leadership of the health education field in Saudi Arabia. Health education has evolved into a profession that requires continuous training to face both current and future challenges.

\section{References}

1. World Health Organization. Health education. From: www. who.int/topics/health_education/en/ Accessed: Feb 2016.

2. Gold RS, Miner KR; 2000 Joint Committee on Health Education and Promotion Terminology. Report of the 2000 Joint Committee on Health Education and Promotion Terminology. J Sch Health 2002; 72:3-7. doi: 10.1111/j.1746-1561.2002. tb06501.x.

3. International Hospital Online. Healthcare in the Gulf: Challenges remain in spite of investment boom. From: www. ihe-online.com/feature-articles/healthcare-in-the-gulfchallenges-remain-in-spite-of-investment-boom/index.html Accessed: Feb 2016.

4. Qureshi NA, Al-Amri AH, Abdelgadir MH, El-Haraka EA. Traditional cautery among psychiatric patients in Saudi Arabia. Transcult Psychiatry 1998; 35:75-83. doi: 10.11 77/136346159803500103.

5. Al-Rowais N, Al-Faris E, Mohammad AG, Al-Rukban M, Abdulghani HM. Traditional healers in Riyadh region: Reasons and health problems for seeking their advice - A household survey. J Altern Complement Med 2010; 16:199-204. doi: $10.1089 / \mathrm{acm} .2009 .0283$.

6. Al-Harthi F. Health over a century. Riyadh, Saudi Arabia: Ministry of Health, 1999.

7. Memish ZA. The Hajj: Communicable and non-communicable health hazards and current guidance for pilgrims. Euro Surveill 2010; $15: 19671$.

8. Saudi Arabia Ministry of Health. About the ministry. From: www.moh.gov.sa/en/Ministry/About/Pages/default.aspx Accessed: Feb 2016.

9. Almalki M, Fitzgerald G, Clark M. Health care system in Saudi Arabia: An overview. East Mediterr Health J 2011; 17:784-93.

10. Hamdan A. Women and education in Saudi Arabia: Challenges and achievements. Int Educ J 2005; 6:42-64.

11. Al-Yousuf M, Akerele TM, Al-Mazrou YY. Organization of the Saudi health system. East Mediterr Health J 2002; 8:645-53.

12. Aldossary A, While A, Barriball L. Health care and nursing in Saudi Arabia. Int Nurs Rev 2008; 55:125-8. doi: 10.1111/j.14667657.2007.00596.x.

13. Khaliq AA. The Saudi health care system: A view from the minaret. World Health Popul 2012; 13:52-64. doi: 10.12927/ whp.2012.22875.
14. Saudi Arabia Ministry of Health. Health statistical yearbook 2014. From: www.moh.gov.sa/Ministry/Statistics/book/Pages/ default.aspx Accessed: Feb 2016.

15. Rabah R. Personal communication, March 2014.

16. Al-Houtan A. Launch of training sessions on health education. From: www.alriyadh.com/293028 Accessed: Feb 2016.

17. Buchanan DR. Perspective: A new ethic for health promotion - Reflections on a philosophy of health education for the 21st century. Health Educ Behav 2006; 33:290-304. doi: 10.1177/ 1090198105276221.

18. Saudi Arabia Ministry of Health. Healthy cities project. From: www.moh.gov.sa/depts/EnvironmentalHealth/Departments/ Pages/HealthyCities.aspx Accessed: Feb 2016.

19. Abdullah S. The failure of school health units. From: www. alriyadh.com/864190 Accessed: Feb 2016.

20. Mahfouz AA, Abdelmoneim I, Khan MY, Daffalla AA, Diab MM, Al-Gelban MS, et al. Obesity and related behaviors among adolescent school boys in Abha City, southwestern Saudi Arabia. J Trop Pediatr 2008; 54:120-4. doi: 10.1093/tropej/ fmm089.

21. Al-Ahmadi H, Roland M. Quality of primary health care in Saudi Arabia: A comprehensive review. Int J Qual Health Care 2005; 17:331-46. doi: 10.1093/intqhc/mzi046.

22. Royal Embassy of Saudi Arabia, Washington DC. The basic law of governance. From: www.saudiembassy.net/about/countryinformation/laws/The_Basic_Law_Of_Governance.aspx Accessed: Feb 2016.

23. The Charitable Society for Health Communication. From: www.hayatona.org/mag/ Accessed: Feb 2016.

24. Saudi Arabia Ministry of Culture and Information. National commission for health education will hold its first meeting. From: www.info.gov.sa/Details.aspx?id=1306 Accessed: Feb 2016.

25. Saudi Arabia Ministry of Social Affairs. Charities contact information. From: www.gg.org.sa/ Accessed: Feb 2016.

26. Saudi Commission for Health Specialties. Guide of Professional Classification and Registration for Health Practitioners, 6th ed. From: www.scfhs.org.sa/en/registration/ClassAndRegister/Rer egister/Documents/Professional\%20Classification\%20manual\%20 for\%20Health\%20Practitioners.pdf Accessed: Feb 2016

27. Alkhazim MA. Higher education in Saudi Arabia: Challenges, solutions, and opportunities missed. High Educ Policy 2003; 16:479-86. doi: 10.1057/palgrave.hep.8300035.

28. King Saud bin Abdulaziz University for Health Sciences. College of Public Health \& Health Informatics. From: www.ksau-hs.edu.sa/English/Academic/Colleges/Pages/ PublicHealthandHealthInformatics.aspx Accessed: Feb 2016.

29. College of Applied Medical Sciences, King Saud University. Community Health Sciences Department KSU statistics. From: http://cams.ksu.edu.sa/ar/node/1531 Accessed: Feb 2016.

30. Saudi Arabia Ministry of Education. Certificate equivalency general guidelines. From: www.mohe.gov.sa/en/Ministry/ Deputy-Ministry-for-Educational-Affairs/The-GeneralAdministration-for-Equivalency-certifications/SystemEquation/Pages/Subject-Of-Study.aspx Accessed: Feb 2016. 